\title{
Alcance de la responsabilidad limitada de los socios cooperativistas. Pluralidad de regulaciones
}

(Scope of the limited liability of the cooperative members. Plurality of regulations)

\author{
Miren Epelde Juaristi ${ }^{1}$ \\ Universidad del País Vasco/Euskal Herriko Unibertsitatea (España)
}

Sumario: 1. Introducción. 2. Algunas nociones preliminares. 3. La nueva Ley $11 / 2019$, de 20 de diciembre, de Cooperativas de Euskadi. 3.1. Imputación de pérdidas de la Sociedad Cooperativa. 3.2. Alcance de la imputación de pérdidas. 4. La regulación de la responsabilidad de los socios en otras Comunidades Autónomas. 5. La responsabilidad del socio que causa baja. Especial referencia a la Ley 11/2019 de Cooperativas de Euskadi. 6. Conclusiones. 7. Bibliografía.

Summary: 1. Introduction. 2. Some preliminary notions. 3. The new Law, 11/2019, of 20th December, of Basque Cooperatives. 3.1. Imputation of Cooperative Society losses. 3.2. The range of losses imputation. 4. The regulation of partners' liability in other Autonomous Communities. 5. Partners' liability in their termination. Special mention to Basque Cooperatives Law 11/2019. 6. Conclusions 7. Bibliography.

Resumen: En los tiempos que corren se pone el foco sobre la economía social, entre otras cosas, como vía de salida de la crisis de las empresas. Se prevé que el sistema organizativo de las empresas integradas en este sector pueda contribuir a reestructurar y replantear el rumbo de las sociedades. A tal fin, los poderes públicos, incluidas las instituciones de la Unión Europea, dedican grandes esfuerzos al fomento de la economía social.

Sin embargo, la pluralidad normativa no ayuda a tener una visión global de la misma. En el caso de las Cooperativas, cada Estado y dentro de cada uno, como en el caso español, cada Comunidad Autónoma cuenta con su propia legislación, no siempre acorde o perfectamente alineada con las demás. En este trabajo se realiza un estudio comparativo de las diferentes normativas autonómicas, en concreto sobre el alcance de la responsabilidad limitada de los socios cooperativistas.

1 Departamento de Derecho de la Empresa y Derecho Civil. Universidad del País Vasco/Euskal Herriko Unibertsitatea (UPV/EHU). Orcid: https://orcid.org/0000-00027993-0467. Email: miren.epelde@ehu.eus 
Palabras clave: Sociedad Cooperativa, socios, responsabilidad limitada y responsabilidad ilimitada.

Abstract: Nowadays it seems that the social economic would be the solution for the business to confront the economic crisis. The organizational system of the social economic factories would help to reorganize and reconsider the future of the companies. Moreover, the European Union is working hard on improving the social economic.

However, the variety of regulation doesn't work to have a global vision. In fact, in the case of cooperatives, each community is able to approve its own regulation. Due to that, sometimes the point of view of each regulation disagree with the others. The main goal of this article is to compare the different regulations and analyze how far can the partners' liability arrive.

Keywords: Cooperative Society, partners, partners' limited liability, partners' unlimited liability. 


\section{Introducción}

La población mundial se encuentra inmersa ante un futuro incierto donde se avecina y, a día de hoy, se siente la amenaza de una importante crisis económica post Covid. Desde el comienzo de la pandemia, hacia el mes de enero de 2020 y el posterior confinamiento decretado en marzo (en el caso español), comenzaron a ser notorias las primeras evidencias de crisis económica mundial². Las medidas económicas adoptadas con el fin de ayudar a las empresas y a trabajadores a mantener sus puestos de trabajo han sido de diversa índole y, como fuera impensable en tiempos anteriores, se observa una especial atención hacia las personas. Al fin y al cabo, si las personas pierden las fuentes de ingreso que les son necesarias para poder sobrevivir, la economía de mercado no funciona.

Los economistas conciben el sistema económico sobre la base de tres grandes pilares que son: la economía capitalista, la economía pública y la economía social. Pero, si bien las dos primeras han mantenido un desarrollo dilatado en el tiempo, no ha sucedido así con el tercer pilar que es imprescindible para que el sistema funcione correctamente, en opinión de algunos expertos ${ }^{3}$. Es por ello que, a día de hoy, se vuelve la mirada hacia la economía social y es tan valorada en aras a un mejor funcionamiento del sistema.

Diferentes iniciativas, de diferentes instancias tanto europeas, estatales, como autonómicas, han visto la luz durante la última década con el objeto de fomentar la economía social, en previsión de posibles amenazas de nuevas crisis económicas. La anterior crisis financiera, de los años 2007-2008 y posteriores, causó estragos en las empresas y también daños importantes entre las cooperativas. Pero, sobre todo, en este ámbito, puso también de relieve los problemas derivados de la incertidumbre a la hora de realizar la interpretación y aplicación de las diferentes regulaciones.

Por lo que respecta a nuestro entorno que es el País Vasco, donde es conocida la especial relevancia de las cooperativas en la estructura de su economía ${ }^{4}$, en esos años, se sucedieron innumerables protestas

2 El País, consultado el 30/06/2020: https://elpais.com/economia/2020/04/16/actualidad/1587035630_565470.html

3 Costas A. 2020. XVIII Congreso Internacional de Investigadores en Economía Social, «La Economía Social: herramienta para el fomento del desarrollo sostenible y la reducción de las desigualdades». Organizado por, Ciriec-España, Conferencia inaugural, Mataró.

4 Ortega I. 2018. "Aportación de las Cooperativas al resto del tejido vasco». Universidad de Mondragón, consultado el 03/07/2020: https://www.mondragon.edu/documents/20182/625969/Aportacion+de+las+coop.+a+los+retos+tejido+productivo+va sco+2018/ecd0df3c-72bc-4f4f-9f18-ce35d5821576, 
por parte de los socios trabajadores preocupados por el alcance de su responsabilidad en contextos de crisis e insolvencia de algunas cooperativas. Por ello, partiendo de la incertidumbre y la ambigüedad normativa que existía al respecto en el País Vasco, el trabajo analiza la situación de los socios ante las deudas y las pérdidas generadas en las sociedades cooperativas. Su objetivo principal consiste en aclarar si la responsabilidad de los socios cooperativistas es limitada - como parece que quiere hacer ver el legislador- o si, por el contrario, existen posibles vías por las que declarar la responsabilidad ilimitada de los socios. El estudio tiene en cuenta todo un elenco plural de normas emanadas de las Comunidades Autónomas que cuentan con sus propias leyes en la materia.

\section{Algunas nociones preliminares}

En España las cooperativas están reguladas por diferentes leyes. La ley general de ámbito estatal por la que se rigen es la Ley 27/1999 de 16 de julio de cooperativas (en adelante LC). Sin embargo, cabe la posibilidad de que cada comunidad autónoma apruebe su propia legislación, tal y como ocurre en la práctica. Ello conlleva, obviamente, el riesgo de una fragmentación normativa y de diversidad de interpretaciones, según el tema de que se trate y la comunidad en que nos encontremos. Así, en nuestro caso, en el tema de la responsabilidad de los socios, la pluralidad normativa es evidente y con ello, surgen dudas sobre el alcance de dicha responsabilidad. Esto es, se plantea la cuestión de si efectivamente se trata de una responsabilidad limitada o si, por el contrario, cabe la posibilidad de su extensión.

De forma general, la idea de responsabilidad limitada, en sentido estricto, se entiende como aquélla en la que el socio será responsable personalmente hasta la aportación realizada al capital social. Sin embargo, desde un punto de vista jurídico, habría que matizar esta idea. Como es lógico, la sociedad cooperativa es responsable por los actos acontecidos dentro de su actividad habitual. No obstante, en caso de que la causa de responsabilidad estuviera unida a un hecho concreto individualizable, podría ser el propio socio quien respondiera por lo ocurrido ${ }^{5}$. Póngase como ejemplo el hecho de que la cooperativa asuma obligaciones con terceros y el socio se haya ofrecido como avalista.

5 Fajardo Garcia, G. 1997. La gestión de la cooperativa: responsabilidad de los socios, Tecnos, Madrid, p. 240. 
En la práctica cotidiana, sin embargo, lo típico es que una vez que haya respondido la sociedad cooperativa y no haya sido suficiente para cubrir la totalidad, entre en juego la figura del socio y su responsabilidad personal. Algunos autores no estiman pertinente distinguir la posible responsabilidad individualizada del socio a la que nos hemos referido, ya que, los socios forman parte de la cooperativa y, por lo tanto, participan de los resultados de la misma, que no siempre son negativos. Así, si durante años los resultados de la cooperativa son positivos y los excedentes generados se revierten a favor de los socios, a la inversa, en caso de resultados negativos, deberían de ser también adjudicados a los socios, siempre y cuando los fondos de reserva de la cooperativa no fueran suficientes ${ }^{6}$.

Por otra parte, a este respecto, debe tenerse en cuenta la distinción básica entre los conceptos de deuda y pérdida. Toda obligación contraída por la empresa y que no haya sido cumplida constituye una deuda. Así, atendiendo a la LC (art. 5), es la sociedad cooperativa la que se hace responsable de las deudas sociales generadas en el contexto de la actividad habitual de la empresa, entendiendo por ello que primeramente responderán las aportaciones realizadas por los socios, pero sin perjuicio de la responsabilidad patrimonial universal de la sociedad. En cambio, la pérdida es la disminución del activo de la empresa, esto es, una minoración de sus bienes y derechos. Por ello, cuando una empresa ha tenido pérdidas en un ejercicio económico se dice que ha tenido resultados negativos.

Sin embargo, esta distinción genera ciertas dudas en torno al alcance de la responsabilidad de los socios, ya que, la interpretación de la LC al respecto puede ser diversa. Por un lado, encontramos la mención literal de que la responsabilidad de los socios por las deudas sociales es limitada a la aportación realizada al capital social ${ }^{7}$. Esta disposición es clara y no genera ninguna duda al respecto. Pero, a sensu contrario, en el apartado donde se regula la forma en que han de imputarse las pérdidas (art. 59. LC), no se recoge literalmente esa responsabilidad limitada, por lo que, el tenor literal del texto puede conducir a interpretar que la responsabilidad de los socios no es estrictamente limitada.

En este punto, conviene traer a colación la idea antes mencionada sobre la actuación de la cooperativa y los resultados de la misma. Conviene recordar la concepción de que la cooperativa per se no ob-

6 Fajardo Garcia, G., Idem, 1997, p.241.

7 Ley 27/1999, de 16 de julio, de Cooperativas, art. 15.3. La responsabilidad del socio por las deudas sociales estará limitada a las aportaciones al capital social que hubiera suscrito, estén o no desembolsadas en su totalidad. 
tiene beneficios, sino que los resultados positivos tienen la consideración de excedentes ${ }^{8}$. Al cierre de cada ejercicio económico, la empresa cooperativa obtiene unos resultados que pueden ser positivos o negativos. Cuando son positivos, la empresa se encontrará en una situación económica satisfactoria, pero los resultados también pueden ser negativos. Al generar pérdidas, habrá que ver si el patrimonio de la sociedad es suficiente para cubrirlas con los excedentes de años anteriores que fueron destinados a reservas o si procede realizar una imputación de las mismas a los socios que los percibieron ${ }^{9}$. Una vez realizada la imputación, existirá la posibilidad de que el socio cubra su parte con la aportación realizada al capital social, pero también la posibilidad de que no alcance y deba, por tanto, aportar más cantidad. En ese caso, la aportación se realizaría con cargo al patrimonio personal del socio, que quedaría menoscabado. Pero habrá que verificar si en años anteriores hubo excedentes repartidos entre los socios. Si fuera así, debe reconocerse que, al fin y al cabo, ese patrimonio del socio ha sido originado gracias a la empresa cooperativa.

A pesar de esta concepción, ésta es una cuestión que genera nerviosismo entre los socios, muchas dudas e incertidumbres. A ello hay que añadir que no es fácil observar un criterio unificado, ya que la legislación en cada comunidad autónoma es distinta y, por ende, se ofrecen distintas interpretaciones.

\section{La nueva Ley 11/2019, de 20 de diciembre, de Cooperativas de Euskadi}

Euskadi es una comunidad autónoma con una dilatada historia en materia de cooperativas. En particular, el grupo Mondragón es conocido en todo el mundo y ha sido desde sus inicios un pilar clave para la economía vasca ${ }^{10}$. No en vano ésta fue una de las comunidades autónomas pioneras en la materia, al igual que Andalucía, Cataluña, Navarra y Valencia que, al tener asumida la competencia exclusiva en sus estatutos de autonomía, dictaron las primeras leyes de cooperativas autonómicas, todas ellas objeto de una o varias reformas posteriores ${ }^{11}$.

8 Fajardo Garcia, G., Op.Cit, 1997, p. 241.

9 LC. art. 69.

10 Ortega I, Op.Cit, 2018.

11 Alfonso Sánchez, R. 2009. «La legislación española sobre cooperativas y sociedades laborales: ¿una respuesta adecuada a las necesidades del sector?» CIRIEC-España. Revista jurídica de economía social y cooperativa, n. ${ }^{\circ} 20$, p. 11. 
Con frecuencia los ciclos económicos desembocan en crisis económicas, de mayor o menor envergadura, que afectan a los diferentes sectores de forma distinta. Así, la crisis financiera de los años 20072008 afloró, en el caso del País Vasco, notables ambigüedades de la Ley 4/1993, de 24 de junio de Cooperativas de Euskadi. Entre otras cuestiones, trascendió la relativa al alcance de la responsabilidad de los socios, que fue muy debatida y controvertida y que llevó a solicitar a los poderes legislativos una aclaración al respecto. Tal y como ocurre con la normativa general estatal (arts. 15 y 59 LC), la anterior ley vasca (Ley 4/1993 art. 56) decía que la responsabilidad de los socios por las deudas sociales sería limitada a la aportación realizada al capital social. Este precepto era claro y conciso. Sin embargo, surgía la duda o la posible dualidad de interpretaciones en torno a la regulación de la imputación de pérdidas de la cooperativa.

La posibilidad de imputar dichas pérdidas a los socios que recogía la ley vasca (art. 69), fue fuente de importantes tensiones e inseguridades entre los socios cooperativistas. Cabe destacar a su vez, el Decreto 58/2005, de 29 de marzo, por el que se aprueba el Reglamento de la Ley de Cooperativas de Euskadi, ya que, recogía expresamente la posibilidad de generar un crédito a favor de la cooperativa en caso de baja del socio y fruto de la liquidación de la vinculación societaria del mismo ${ }^{12}$. En el conocido caso de Fagor Electrodomésticos perteneciente al grupo Mondragón, se constató que en la práctica los socios podían llegar a ser imputados responsables por las pérdidas generadas por la cooperativa ${ }^{13}$. Así es, además, como lo entiende parte de la doctrina científica ${ }^{14}$ que no ve impedimento para ello, aunque también hay otro sector que se decanta por una concepción restrictiva o limitada de la imputación de las pérdidas a los socios ${ }^{15}$. No obstante, cabe señalar

12 Decreto 58/2005, de 29 de marzo, por el que se aprueba el Reglamento de la Ley de Cooperativas de Euskadi. art. 12.2. Las pérdidas asumidas y no compensadas serán consideradas como un crédito a favor de la cooperativa que podrá ser ejercitado, aunque el socio haya causado baja voluntaria u obligatoria en la cooperativa.

13 UPAD del Juzgado de Primera Instancia e Instrucción n. ${ }^{\circ} 1$ de Bergara, Sentencia n. ${ }^{\circ}$ 70/2018, de 27 de julio, (Procedimiento ordinario 204/2017-C).

14 Suso Vidal, J.M, Op. Cit, 2004. Asimismo, Paniagua, M. 2005. "La determinación y la distribución de los resultados del ejercicio económico en la Sociedad Cooperativa: propuestas de armonización legislativa», Revista de Derecho de Sociedades, n. ${ }^{\circ} 24$, p. 204.

15 Grimaldos García, M.I. 2009. «El concurso de la cooperativa y su repercusión en el patrimonio personal de los socios», Revista de Derecho Concursal y Paraconcursal, n. ${ }^{\circ} 11$, p. 323-343. En el mismo sentido se pronuncia, Villafañez Perez, I. 2014. Cooperativa y concurso. Estudio de las relaciones jurídicas con sus socios, Marcial Pons, Madrid, p. 261. 
que, en el caso concreto de Fagor, el Juzgado de Primera Instancia de Bergara (Gipuzkoa) atribuyó dicha responsabilidad a los socios por un motivo diferente, esto es, por no haber interpuesto en plazo la acción de reclamación de la responsabilidad extracontractual del grupo Mondragón.

Dada la trascendencia social y económica que tuvo el caso en el ámbito de la comunidad autónoma, representantes de socios y trabajadores vieron la necesidad urgente de abordar la cuestión y exigieron una nueva regulación al respecto. Tras varios años de diálogo, finalmente se aprobó la nueva Ley 11/2019, de 20 de diciembre, de Cooperativas de Euskadi (en adelante LCE), que entró en vigor el 29 de enero de 2020. Entre las modificaciones, la más relevante respecto al tema que nos ocupa quedó recogida en el artículo 73 relativo a la imputación de pérdidas, a cuyo análisis procedemos a continuación.

\subsection{Imputación de pérdidas de la Sociedad Cooperativa}

En la nueva regulación (art. 73.1 LCE) se recoge, en primer lugar, una vía estatutaria al efecto, es decir, la posibilidad de que en los estatutos de la sociedad cooperativa se fijen los criterios para esa compensación de las pérdidas, en cuyo caso, deben sujetarse a determinadas reglas. (a) La sociedad puede imputar la totalidad de las pérdidas a los fondos de reserva voluntarios. (b) Pero no puede imputar todas las pérdidas al fondo de reserva obligatorio. Como máximo, se permite el porcentaje medio destinado a los fondos legalmente obligatorios en los últimos cinco años. No obstante, se flexibiliza este límite en caso de que el fondo de reserva obligatorio supere el $50 \%$ del capital social de la cooperativa. En tal caso, se permite que el importe que exceda dicho porcentaje sea empleado para compensar las pérdidas. (c) Finalmente, en caso de que ninguna de las dos vías anteriores sea suficiente para cubrir las pérdidas generadas, la sociedad podrá entonces imputar las pérdidas a los socios cooperativistas, en proporción a las operaciones, servicios o actividades realizadas por cada uno de ellos ${ }^{16}$ (Si estos servi-

16 Ley 11/2019, de 20 de diciembre, de Cooperativas de Euskadi, art. 73.2. Las pérdidas imputadas a cada persona socia se satisfarán de alguna de las formas siguientes, según acuerde la asamblea general:

a) Directamente o mediante deducciones en sus aportaciones al capital social o, en su caso, en cualquier inversión financiera de la persona socia en la cooperativa que permita esta imputación, dentro del ejercicio siguiente a aquel en que se hubieran producido. 
cios u operaciones fueran inferiores a los que, como mínimo, está obligado a realizar cada socio, la imputación de las pérdidas habrá de ser proporcional a la actividad coooperativizada mínima obligatoria. Vid. art. 73.1.).

Sin perjuicio de lo anterior, la nueva regulación prevé asimismo una segunda vía extraestatutaria para compensar las pérdidas de la sociedad (art. 73.3 LCE). Contempla la opción de imputarlas a una cuenta especial, para su amortización con cargo a excedentes futuros, dentro del plazo máximo de cinco años. Transcurrido ese tiempo, las pérdidas que queden sin compensar deberán ser satisfechas de conformidad con el régimen establecido para la vía estatutaria (art. 73.1.a), b), c) LCE) en el plazo de un año.

Este sistema de carácter dispositivo, asentado sobre la opcionalidad de estas dos vías, se completa con una novedosa norma de cierre imperativa contenida en el apartado cuarto del citado artículo 73 LCE. El precepto establece que, si transcurridos todos los plazos antes indicados quedaran pérdidas por compensar, éstas serán satisfechas (es decir, deberán ser satisfechas) mediante nuevas aportaciones acordadas por la asamblea general o mediante las nuevas aportaciones que sean necesarias para mantener la condición de persona socia en la cooperativa. Asimismo, impone que el socio deba causar baja en caso de que sus aportaciones queden por debajo del mínimo estatutariamente establecido y no realice nuevas aportaciones (todo ello, obviamente, con independencia de que la cooperativa deba instar el concurso conforme a la ley concursal). Es decir, dicho de otro modo, este apartado se refiere a una ampliación de capital necesaria (u obligatoria) de la cooperativa, para así poder obtener liquidez y hacer frente a las pérdidas, en caso de que las dos vías anteriores no fueran suficientes para ello.

Llegados a este punto, nos preguntamos acerca de la verdadera intención del legislador al respecto ¿cuál es la teleología de la norma? Con esta nueva medida ¿se pretende ciertamente blindar el patrimonio del socio cooperativista? Esa parecía ser la idea o finalidad originaria cuando se inició el proceso de reforma de la ley. ¿O simplemente se trata de articular una vía menos sacrificada para hacer frente a las pérdidas de la empresa? Esa parece ser, más bien, la idea final.

La exposición de motivos de la ley no sirve de mucho para arrojar luz al respecto. En su apartado VII dedicado al régimen económico se limita a señalar que la ley «aclara y delimita con mayor precisión la res-

b) Con cargo a los retornos que puedan corresponder a la persona socia en los cinco años siguientes. Si quedasen pérdidas sin compensar, estas deberán ser satisfechas por la persona socia en el plazo máximo de un año. 
ponsabilidad de la sociedad y de las personas socias frente a terceras personas no socias, así como el régimen de imputación de pérdidas en el seno de la cooperativa» y que «la responsabilidad es limitada, tal y como lo ha sido desde 1993».

Con esta solución innovadora, podría pensarse tal vez, que el legislador ${ }^{17}$ ha querido articular una nueva vía de inversión para los socios cooperativistas, ya que, en sentido estricto, una ampliación de capital supone tener la posibilidad de aumentar la participación en la empresa. Así, desde este punto de vista, no se estaría menoscabando el patrimonio del socio sino, al contrario, ello conllevaría un intento de mejora. Sin embargo, en este contexto, ese intento de mejora se lleva a cabo a la vista de unas pérdidas existentes que serán cubiertas con futuros excedentes, en el caso de que los hubiera.

Por tanto, cabe afirmar que la solución no es del todo liberadora para los socios. Pero tampoco puede obviarse la particularidad de esta figura societaria en la que, como ya se ha mencionado, si los excedentes se reparten entre los socios, puede parecer pertinente adoptar la misma dinámica en el caso de la disminución del patrimonio de la cooperativa. Debería ser lo razonable según buena parte de la doctrina ${ }^{18}$.

\subsection{Alcance de la imputación de pérdidas}

Junto a esta cuestión se plantea la interrogante de si la imputación de pérdidas ha de afectar a todo el patrimonio presente y futuro del socio o si, por el contrario, debería limitarse en función de los excedentes percibidos en los años de pertenencia a la cooperativa. Esto es, ¿el socio debería hacer frente con todo su patrimonio? ¿o respondería con el capital social aportado y con los excedentes recibidos durante su condición de socio?

Al respecto, algunos autores defienden que la responsabilidad del socio debería ser universal en virtud del artículo 1911 del Código Civil, quedando a salvo algunas excepciones ${ }^{19}$. Así, por ejemplo, en las cooperativas de trabajo asociado procede el reparto entre los socios traba-

17 LCE. art. 73.4.

18 A favor de la idea se expresan, Fajardo Garcia, G.: op.cit., 1997, pp. 241, Viteri Zubia, I. 2016. "La responsabilidad del socio cooperativista por las pérdidas sociales», CIRIEC-España. Revista Jurídica de economía social y cooperativa, n. ${ }^{\circ} 28$, p. 225 , Suso Vidal J.M. 2004. "La imputación de pérdidas al socio en la liquidación concursal cooperativa», Estudios sobre la ley Concursal. Libro homenaje a Manuel Olivencia, vol. 5, Marcial Pons, Madrid, p. 4860.

19 Fajardo Garcia, G.: Op. Cit., 1997, p. 243. 
jadores de los excedentes y de las pérdidas, pero entre el anticipo y el retorno a percibir se les debería garantizar, al menos, el salario mínimo interprofesional. Esa debería ser la cantidad mínima que fueran a percibir. Ahora bien, de esta excepción se podría concluir que, si el socio trabajador tiene asegurada una retribución fija, no está haciendo frente a las pérdidas de la cooperativa.

En su lugar podría plantearse otra posibilidad, que el socio trabajador percibiera una retribución por el trabajo realizado y que no se realizara ningún reparto de resultados, ya fueran positivos o negativos. En ese caso, estos últimos deberían imputarse al patrimonio irrepartible, para que de esta forma la sociedad pudiera hacer frente a las pérdidas generadas. De esta manera, el socio se aseguraría una retribución, que podría coincidir o no con el salario mínimo interprofesional, y se evitarían tanto el beneficio directo derivado de los resultados positivos como el consiguiente perjuicio de los negativos.

También existe una ulterior posibilidad al respecto, que ha sido adoptada únicamente por la comunidad valenciana. Según su Ley 2/ 2015 de cooperativas de Valencia (art. 69.3) los socios cooperativistas responderán hasta los anticipos recibidos y el capital social aportado. A partir de ahí, si hubiera más pérdidas habría que imputarlas al patrimonio social. De esta forma, la responsabilidad de los socios cooperativistas queda efectivamente limitada. Como veremos más adelante, las posibilidades al respecto son variadas a tenor de la variedad normativa existente.

En el otro lado, en cambio, otro sector de la doctrina considera que la responsabilidad de los socios cooperativistas debe ser siempre limitada, aunque sin perjuicio de que, en caso de imputación de pérdidas, éstas puedan serles imputadas ${ }^{20}$. Estiman que, dicha imputación tiene su límite en la aportación realizada al capital social, sin que pueda exceder de la misma. En ese contexto, si con la imputación de pérdidas la aportación realizada al capital social se viera disminuida y ya no cumpliera con el importe mínimo requerido para ostentar el título de socio, éste debería decidir entre: darse de baja o bien volver a reinvertir para mantener así su condición. Sería similar a lo que ocurriría en caso de que la sociedad cooperativa no tuviera suficiente capital como para poder seguir siendo considerada cooperativa. Esto es, tendría que elegir entre disolverse o aportar el capital mínimo necesario para mantener la figura societaria.

20 Al respecto se menciona, Villafañez Perez I. 2020. «El Régimen orgánico y económico de las cooperativas a la luz de la nueva Ley de cooperativas de Euskadi», Revista de derecho de sociedades, n. ${ }^{\circ}$ 60, Aranzadi. Edición en PDF. DOI: https://dialnet.unirioja.es/servlet/extart?codigo $=7621638$ 
En definitiva, si bien hay una posición en contra de admitir la responsabilidad ilimitada de los socios ${ }^{21}$, choca con otros que entienden que esa responsabilidad limitada entra en colisión con la imputación de pérdidas a los socios 22 . A este respecto, los autores que admiten la responsabilidad ilimitada de los socios se apoyan en que las pérdidas que se les son imputables, son patrimoniales de cada uno de ellos y no de la cooperativa. Ésa sería la razón por la que les son imputables, con independencia de las pérdidas sociales ${ }^{23}$. A su entender, habría que verificar de donde proviene la generación de la pérdida, si de una acción individualizable del socio o de actividades cooperativas con terceros. La pérdida sería imputable al socio en el primer supuesto, pero no en el segundo.

\section{La regulación de la responsabilidad de los socios en otras Comunidades Autónomas}

La Constitución Española contiene el mandato a los poderes públicos para que incentiven la participación de los trabajadores en la empresa (art. 129.2) y para que, con una normativa adecuada para ello, fomenten la existencia de sociedades cooperativas. Sin embargo, en la distribución de competencias a las Comunidades Autónomas (arts. 148-149 Const.) no se hace constar expresamente que dicha competencia sea exclusiva de las autonomías, pero, cabe interpretarla implícitamente, por lo que numerosas comunidades hicieron suya esa competencia. Aquéllas que vieron la necesidad de regulación en la materia aprobaron su propia ley, lo que desencadenó la existencia de una pluralidad normativa y una gran variedad de interpretaciones en torno a la responsabilidad de los socios, entre otras cuestiones ${ }^{24}$.

21 Paz Canalejo, N., 1979. El nuevo derecho cooperativo español, Digesa, Madrid, p. 197.

22 Elena Diaz, F., 1975-1976. «ldeas sobre una posible interpretación de las pérdidas del pasivo según la vigente ley», Estudios cooperativos n. ${ }^{\circ}$ 36-38, p. 204.

23 Al respecto, Manrique Romero, F. y Rodríguez Poyo-Guerrero, J.M. 1980. «La cooperativa: garantías formales para su eficacia en el tráfico», Revista de Derecho Notarial, n. ${ }^{\circ} 109-110$, p. 46. "El que, en una sociedad, sea o no de responsabilidad limitada, se considere regla normal que las pérdidas del ejercicio, no imputadas al fondo de reserva, no se soporten tampoco por el patrimonio social, sino que sean sufragadas por los socios, no puede tener otra explicación que la de que la pérdida no es de la sociedad, sino del socio directamente. Asimismo, Vicent Chuliá, F. 1994. Ley general de cooperativas, Tomo XX de los Comentario a al Código de comercio y Legislación mercantil Especial, vol. 3. ${ }^{\circ}$, Madrid, p. 142.

24 Alfonso Sánchez, R., Op. Cit., 2009, p. 12. 
En Andalucía, por ejemplo, su ley de cooperativas (en adelante LCA) establece que la responsabilidad de los socios por las deudas de la cooperativa será limitada ${ }^{25}$, lo cual no plantea dudas. Además, en el caso de imputación de pérdidas, el legislador andaluz redactó claramente la posibilidad de imputar las pérdidas a los socios, pero con el límite de la aportación realizada al capital social ${ }^{26}$. Por tanto, no se plantean dificultades de interpretación de la norma, ya que, toda responsabilidad queda limitada a la aportación realizada por el socio al capital social.

En el caso de Madrid, la ley de cooperativas (en adelante LCM) establece igualmente que la responsabilidad de los socios ante las deudas será limitada hasta la aportación realizada al capital social. Pero en este caso, se acepta la posibilidad de que en los estatutos se pueda ampliar dicha responsabilidad ${ }^{27}$. Respecto a la imputación de pérdidas ${ }^{28}$, el le-

25 Ley 14/2011 de, 23 de diciembre, de Sociedades Cooperativas Andaluzas, art. 53.2. La responsabilidad de los socios y socias por las deudas sociales quedará limitada al importe de las aportaciones suscritas al capital social, estén o no desembolsadas.

${ }^{26}$ LCA. art. 69.2. 2. Las pérdidas se compensarán conforme a los siguientes criterios: a) Cuando la sociedad cooperativa tuviese constituido algún fondo de reserva voluntario, la Asamblea General podrá determinar que todas o parte de las pérdidas se imputen a dicho fondo $y$, de no cubrirse en su totalidad, las pérdidas sobrantes se imputarán en la forma señalada en las letras b) y c). b) Al Fondo de Reserva Obligatorio podrá imputarse el porcentaje que determine la Asamblea General, sin que el mismo pueda exceder del cincuenta por ciento de las pérdidas. Si como consecuencia de dicha imputación, el fondo quedase reducido a una cifra inferior a la mitad del capital estatutario, la sociedad deberá reponerlo de manera inmediata, con cargo a reservas voluntarias si existiesen y fuesen suficientes, o con el resultado positivo de futuros ejercicios económicos. c) La diferencia resultante, en su caso, se imputará a cada persona socia en proporción a las operaciones, servicios o actividades cooperativizadas efectivamente realizados por cada una de ellas. Si esta actividad fuese inferior a la que estuviese obligada a realizar conforme a lo establecido en los estatutos, la imputación de las pérdidas se efectuará en proporción a esa participación mínima obligatoria fijada estatutariamente. Las pérdidas se imputarán al socio o socia hasta el límite de sus aportaciones al capital social.

27 Ley 4/1999, de 30 de marzo, de cooperativas de la Comunidad de Madrid, art. 5.3. Si los Estatutos lo prevén, podrá exigirse una responsabilidad adicional del socio para el caso de insolvencia de la cooperativa o una responsabilidad ilimitada por las deudas sociales. En estos casos, la responsabilidad entre los socios será mancomunada, salvo previsión contraria en los Estatutos.

28 LCM. art. 61.1. Las pérdidas extracooperativas y extraordinarias se imputarán a la reserva obligatoria o voluntaria y, si éstas fuesen insuficientes, la diferencia se recogerá en una cuenta especial para su amortización con cargo a futuros beneficios, dentro del plazo máximo de siete años. En el caso de que tuviese que reducirse el capital social en compensación de estas pérdidas se reducirán las aportaciones de los socios y asociados en proporción al capital suscrito por cada uno, pero en el caso de los socios se iniciará la imputación por las aportaciones obligatorias. 
gislador madrileño distingue dos situaciones ${ }^{29}$. Por un lado, las pérdidas generadas extracooperativamente y las extraordinarias y por otra, las pérdidas generadas en el funcionamiento normal de la cooperativa. Por las primeras el socio respondería con el límite de la aportación realizada al capital social, sin embargo, en el segundo supuesto la responsabilidad no quedaría limitada al capital social. Esto es, se entiende que el socio debe de responder con su patrimonio en lo relativo a la actividad normal de la cooperativa. Como se ha mencionado, teniendo en cuenta la posición de algunos autores ${ }^{30}$, el socio deberá de responder tanto por los resultados positivos como los negativos de la sociedad cooperativa.

Sin embargo, se trata éste de un régimen de carácter dispositivo que permite su variación a través de los estatutos de la cooperativa. Así, aunque la ley regule que los socios han de responder limitadamente ante deudas sociales, en los estatutos puede redactase otra cosa sobre la base de determinadas causas razonadas. Este modelo es el reflejado también en la normativa de otras comunidades autónomas como Cataluña y Navarra ${ }^{31}$.

Otro ejemplo interesante es el de la Ley de Cooperativas de la Comunidad Valenciana (en adelante LCV). Como ocurre en el caso de Madrid, el legislador abre la posibilidad de ampliar la responsabilidad

29 LCM. art. 61.2. La compensación de las pérdidas derivadas de la actividad cooperativizada con los socios habrá de sujetarse a las siguientes normas: a) A la reserva voluntaria creada para este fin podrán imputarse la totalidad de las pérdidas. b) A la reserva obligatoria podrá imputarse como máximo el 50 por 100 de las pérdidas o el porcentaje medio de los excedentes operativos que se hayan destinado a las respectivas reservas en los últimos cinco años, o desde la constitución de la cooperativa si ésta tiene menos de cinco años de antigüedad. c) La cuantía no compensada con las reservas se imputará a los socios en proporción a las operaciones o servicios cooperativizados realizados por cada uno de ellos con la cooperativa. Si estas operaciones o servicios realizados fueran inferiores a los que como mínimo está obligado a realizar el socio, conforme a lo establecido en los Estatutos, la imputación de las referidas pérdidas se efectuará en proporción a la actividad cooperativizada mínima obligatoria.

30 Autores a favor de la idea, Fajardo Garcia, G. 1997, Viteri Zubia, I. 2016, Suso Vidal J.M. 2004.

31 Ley 18/2002, de 5 de julio, de Cooperativas de Catalunya. art. 54. Salvo que los estatutos sociales dispongan lo contrario, los socios han de responder de las deudas sociales de forma limitada a las aportaciones al capital social suscritas, tanto si son desembolsadas como si no. Asimismo, Ley Foral 14/2006, de 11 de diciembre, de Cooperativas de Navarra, (en adelante LCFN) art. 8.1. La responsabilidad de los socios podrá ser limitada o ilimitada según dispongan los estatutos. A falta de disposición expresa, la responsabilidad de los socios por las deudas sociales frente a terceros estará limitada a las aportaciones al capital social suscritas, con independencia de que estén o no desembolsadas. 
de los socios mediante estatutos ${ }^{32}$. En este caso es en los estatutos donde se decidirá cómo habrá de ser dicha imputación. El legislador se limita a regular que los socios responderán por las actividades cooperativas, con los anticipos recibidos durante la actividad económica, con el capital social y con su participación en las reservas repartibles ${ }^{33}$. De este modo, la responsabilidad por las pérdidas extracooperativas y extraordinarias queda fuera del alcance de la responsabilidad de los socios, según la ley, de carácter dispositivo.

La ley de Cooperativas de Castilla y León (en adelante LCCL) recoge la misma fórmula que regía en la ley anterior de cooperativas de Euskadi. Se trata, por lo tanto, de una regulación que puede dar lugar a discrepancias a la hora de interpretar y determinar la responsabilidad de los socios ${ }^{34}$.

Se observa que existen comunidades autónomas que distinguen los tipos de pérdidas que puede haber y los regulan de forma distinta. Diferencian las pérdidas generadas en la actividad cotidiana de la cooperativa, donde estaría presente la responsabilidad del socio, de las pérdidas extracooperativas y extraordinarias, donde el socio no es considerado responsable. Es el modelo que siguen además de las ya mencionadas Madrid y Valencia, las leyes de, Extremadura, Aragón y Andalucía. En el otro lado están las regulaciones que no matizan el tipo de pérdidas, entre las que se encuentran Euskadi, Navarra, Galicia, Castilla y León, Castilla la Mancha, Cataluña e Islas Baleares.

Ésta es una distinción clave, ya que dependiendo del territorio en que nos encontremos, cabrá la posibilidad de que a los socios se les im-

32 Decreto Legislativo 2/2015, de 15 de mayo, del Consell por el que se aprueba el texto refundido de la Ley de Cooperativas de la Comunitat Valenciana. art 4.2. La responsabilidad de las personas socias por las deudas sociales quedará limitada al importe nominal de las aportaciones al capital social. Los estatutos podrán establecer una responsabilidad adicional para el caso de insolvencia de la cooperativa. La responsabilidad de los socios y socias por las deudas sociales será ilimitada cuando los estatutos de la cooperativa lo determinen expresamente. En este caso la responsabilidad entre ellas será mancomunada simple, salvo que los propios estatutos la declaren de carácter solidario.

33 LCV. art. 69.1. Los estatutos deberán fijar los criterios de compensación de las pérdidas derivadas de la actividad cooperativizada con las personas socias. Asimismo, art. 69.3. Si los estatutos sociales lo establecen, las pérdidas derivadas de la actividad cooperativizada con las personas socias que se imputen a estas, alcanzarán como máximo el importe total de los anticipos asignados a las personas socias en el ejercicio económico, más sus aportaciones a capital social y su participación en las reservas repartibles.

34 Ley 4/2002, de 11 de abril, de Cooperativas de la Comunidad de Castilla y León. En relación a la responsabilidad de las deudas sociales, art 67 . En relación a la imputación de pérdidas, art. 75. 
pute la cobertura de todas las pérdidas o solo de las relativas a la actividad diaria de la sociedad. En ese caso, el socio deberá asumir el hecho de que durante su trayectoria como socio habrá de hacer frente a las posibles pérdidas que se vayan a generar en el seno de la cooperativa.

Sin embargo, en el caso concreto de Euskadi, el legislador parece haber intentado con la nueva ley que el socio pueda librarse de esa responsabilidad, aprobando la posibilidad de realizar una ampliación de capital y tratar así de que no se menoscabe su patrimonio ${ }^{35}$. Pero claro está que la intención de no menoscabar el patrimonio de los socios, no trae consigo la desaparición de las pérdidas. Esas pérdidas seguirán existiendo y habrá de hacerles frente, solo que se ofrece a los socios la posibilidad de cubrirlas con las nuevas aportaciones realizadas para aumentar el capital. En definitiva, en vez de minorar negativamente su patrimonio, este mecanismo ofrece una connotación positiva de la situación entendiéndola como una inversión a futuro, aunque puede llegar a no ser positiva para los trabajadores.

Por su parte, otras comunidades han optado directamente por diferenciar la procedencia de la pérdida generada, para así discernir acerca de la posible desvinculación de dicha responsabilidad al socio. Pero no niegan en ningún momento su responsabilidad por las pérdidas generadas en la actividad diaria de la empresa. A su vez, algunas comunidades como Andalucía, expresan claramente su intención de limitar la responsabilidad de los socios a la aportación realizada, sin ningún género de dudas o entendimientos erróneos sobre una responsabilidad ilimitada ${ }^{36}$. En el caso de la Comunidad Valenciana, entiende que, si los estatutos recogieran expresamente la posibilidad de una responsabilidad ilimitada de los socios, ésta será considerada como tal.

\section{La responsabilidad del socio que causa baja. Especial referencia a la Ley 11/2019 de Cooperativas de Euskadi}

El alcance de la responsabilidad del socio cooperativista plantea diferentes escenarios, pues el socio no es solo responsable durante su

35 Otxoa Errarte R. 2019. "A propósito del Laudo del Servicio Vasco de Arbitraje Cooperativo n. ${ }^{\circ} 7 / 2018$, del 20 de julio de 2018. Doble contabilidad y asunción de pérdidas», Revista Vasca de Economía Social, 16, p. 183, DOI: https://doi. org/10.1387/reves.21220.

36 Sacristan Bergia, F. 2020. "Sobre la limitación de la responsabilidad de los socios cooperativistas», Boletín de la Asociación Internacional de Derecho Cooperativo, n. ${ }^{\circ} 57$, Bilbao, p. 240, DOI: https://doi.org/10.18543/baidc-57-2020pp225-251 
condición de socio, sino que el hecho de darse de baja puede no constituir el final de su relación con la cooperativa. A este respecto, también son variadas las normativas de las comunidades autónomas, por lo que se contemplan diferentes situaciones en torno al socio que ha causado baja y al alcance de su responsabilidad.

A nivel estatal, la ley recoge que este seguirá siendo responsable por las deudas sociales durante los cinco años siguientes a su baja ${ }^{37}$. Sin embargo, aunque parte las comunidades autónomas comparten esta regulación, hay algunas que se basan en criterios diferentes. Se asemejan a la regulación estatal las comunidades autónomas de Madrid (LCM, art. 55.5), Castilla y León (LCCL, art. 67), Navarra (LCFN, art. 23.3) y Valencia (LCV, art. 24.1) entre otras. En ellas se entiende que el socio cooperativista, aunque cause baja seguirá siendo responsable de las obligaciones adquiridas los próximos cinco años. Esta idea se fundamenta en la idea de que no debe existir un enriquecimiento injusto o desigualdades entre los socios que se quedan en la cooperativa y los que se van ${ }^{38}$.

Sin embargo, en el caso de Euskadi, según la ley anterior (Ley 4/1993 de Cooperativas de Euskadi) el socio que hubiera causado baja no seguiría siendo responsable por las deudas sociales ${ }^{39}$. Esto es, el socio que quisiera causar baja, independientemente de si fuera justificada o no justificada ${ }^{40}$, una vez se le hubiera determinado el importe a percibir por su marcha, no sería responsable por las deudas sociales. Por el contrario, la nueva ley entiende oportuno hacer responsable al socio, en caso de que hubiera algún contrato firmado durante el periodo de actividad del mismo y siguiera vigente, y por ende, generase responsabilidad, aún después de que el socio haya abandonado la cooperativa ${ }^{41}$. Esto es, el

37 LC. art. 15.4. No obstante, el socio que cause baja en la cooperativa responderá personalmente por las deudas sociales, previa exclusión del haber social, durante cinco años desde la pérdida de su condición de socio, por las obligaciones contraídas por la cooperativa con anterioridad a su baja, hasta el importe reembolsado de sus aportaciones al capital social.

38 Sacristan Bergia F., Op.Cit., 2020, p. 236.

39 Ley 4/1993, de 24 de junio, de Cooperativas de Euskadi, art. 56.2. Una vez fijado el importe de las aportaciones a reembolsar, los socios que causen baja, no tendrán responsabilidad alguna por las deudas que hubiese contraído la cooperativa con anterioridad a su baja.

40 Gondra Elguezabal G. y Bilbao Zorrozua, A. 2019. "Alcance del régimen de responsabilidad de los socios en las cooperativas de viviendas en Euskadi», Revista Vasca de Economía Social, n. ${ }^{\circ}$ 16, p. 151, DOI: https://doi.org/10.1387/reves.21217.

${ }^{41}$ LCE. art. 59.4. Las personas socias que hubieran, expresa y especificamente, suscrito contratos o asumido obligaciones con la sociedad cooperativa y que, por su naturaleza, no se extinguen con la pérdida de la condición de persona socia responderán de su cumplimiento aún después de causar baja. 
ex socio seguirá siendo responsable por lo que pueda ocurrir con los contratos que fueron acordados durante su actividad cooperativa y que tras su baja estuvieran en vigor. Debe entenderse que el legislador vasco ha optado por una vía de igualdad para los socios y tratando de evitar así cualquier enriquecimiento injusto.

Ahora bien, tal y como ocurre con los socios de la cooperativa, debe aclararse el alcance de dicha responsabilidad. Tras el análisis de las diferentes regulaciones de las comunidades autónomas, se observa que esta responsabilidad se limita a la aportación realizada al capital social ${ }^{42}$. Esto es, el socio que se dé de baja seguirá siendo responsable por las obligaciones contraídas cuando formaba parte de la cooperativa, pero responde únicamente hasta el importe de la liquidación realizada por su salida.

El hecho de darse de baja lleva consigo el derecho de reembolso del socio, sobre la aportación que realizó al capital social para obtener la condición de socio ${ }^{43}$. Este derecho de reembolso es cuestionado por algunos autores, que por sus características, prefieren calificarlo como derecho de liquidación de la aportación realizada44. Matizan que la aportación al capital realizada en su día, con el transcurso del tiempo y las circunstancias de la actividad económica de la sociedad, puede no corresponder exactamente con la aportación a reembolsar. Es por ello que se decantan por el concepto de liquidación de la aportación realizada. Dicho de una forma más técnica, la contribución al capital social ha de actualizarse conforme los excedentes repartibles y las pérdidas imputables de la sociedad, en relación al resultado de su actividad ${ }^{45}$.

El derecho de liquidación normalmente no se suele ejecutar inmediatamente a la salida del socio de la cooperativa, por lo que, si el ex socio tuviera que responder con la aportación realizada, es posible que todavía se encuentre en el haber social de la cooperativa ${ }^{46}$. Aquí

42 Sacristan Bergia F., Op.Cit., 2020, p. 236.

43 LC. art. 45.1.a). El capital social estará constituido por las aportaciones obligatorias y voluntarias de los socios, que podrán ser: a) aportaciones con derecho de reembolso en caso de baja.

44 Vargas Vasserot, C. 2010. «El derecho de reembolso del socio en caso de baja y el concurso de las sociedades cooperativas», CIRIEC-España. Revista Jurídica de economía social y cooperativa, n. ${ }^{\circ} 21$, p. 41.

45 Viguera Revuelta, R. 2015. El Derecho de reembolso en las sociedades cooperativas, Tirant lo Blanch, Valencia, p. 115.

46 Bataller Grau, J. (dir.), et al., 2012. Pérdidas, disolución y concurso en sociedades cooperativas, Marcial Pons, Madrid, p. 133. 
también hay autores que reclaman la devolución inmediata de dicho importe ${ }^{47}$.

Respecto al alcance de la responsabilidad del socio, más allá de que sea limitada o no, lo importante es determinar por qué deudas responde el socio, si es por las ya generadas durante su vigencia como socio y era conocedor de ellas o si debe también responder por las creadas con posterioridad a su baja en la sociedad. Este es otro tema debatido entre los expertos. Para algunos, aceptar las dos posibilidades sería correcto ${ }^{48}$. Entendiendo que el socio sigue siendo responsable durante los cinco años siguientes y las deudas contraídas puedan ser consecuencia de decisiones tomadas durante su pertenencia a la sociedad. Sin embargo, la LC no lo recoge así. El legislador entiende que es necesario que las deudas fueran generadas durante su vinculación a la cooperativa en calidad de socio y no a posteriori ${ }^{49}$. Ésta es una solución que conjuga con la lógica del reparto de bienes, y que se aplica en el caso de reparto de responsabilidad por deudas. Esto es, el socio deberá de responder por las deudas generadas durante su estancia activa en la sociedad. Se entiende por lo tanto que cabe la posibilidad de establecer la responsabilidad del socio que haya causado baja, no por ello, convirtiéndolo en una responsabilidad ilimitada, pero sí utilizando la lógica de que, si existen contratos vigentes después de su marcha, suscritos con anterioridad y con su conocimiento, éste debe responder por ellos.

Así ocurre también en las diferentes comunidades autónomas en donde los legisladores estiman que el socio que se da de baja responderá por las obligaciones contraídas durante su permanencia en la empresa (LCE art. 59.4, LC. Valencia art. 24.1, LC. Madrid art.55.5, LC. Castilla y León art. 67 y LC. Foral de Navarra art.23.3).

\section{Conclusiones}

Se dice que la economía suele ir marcada por ciclos económicos sucesivos de crecimiento y de crisis. Así está ocurriendo con la pandemia actual, siendo las repercusiones una montaña rusa para la economía glo-

47 Aparicio, I.N. 2019. "Reflexiones sobre diversas cuestiones cooperativas (análisis principal bajo Ley Vasca)», Deusto Estudios Cooperativos, n. ${ }^{\circ} 13$, p. 46.

48 Paz Canalejo, N. 1979. El nuevo derecho cooperativo español, Digesa, Madrid, p. 196-197.

49 LC. art. 15.4. por las obligaciones contraídas por la cooperativa con anterioridad a su baja. 
bal. Estos altibajos arrojan indicadores del buen o mejorable camino que puede llevar la actividad económica y de su estudio se derivan reflexiones sobre posibles cambios normativos para mejorar dicha actividad.

En relación a las cooperativas y a la responsabilidad de los socios, el marco jurídico estatal plantea diferentes interpretaciones en materia de imputación de pérdidas, ya que, no se especifica claramente hasta dónde llega su alcance. No ocurre así con la responsabilidad del socio por deudas de la cooperativa, para la que se prevé expresamente que la responsabilidad del socio será limitada, con excepción de alguna comunidad autónoma que admite la ampliación de la responsabilidad por vía estatuaría (en el caso de Andalucía). Sin embargo, la imputación de pérdidas acusa una situación de fragmentación normativa entre las diferentes leyes de las comunidades autónomas. Algunas contemplan una salida clara y concreta a la cuestión, como la ley de la comunidad autónoma de Valencia, aceptando que la responsabilidad del socio pueda ser ilimitada. Pero, en general, esta pluralidad normativa no ha contribuido a la claridad y la ley principal estatal parece haber operado simplemente como guía para los legisladores autonómicos.

En Euskadi, la pasada crisis financiera sacó a la luz las imprecisiones de la ley y las dudas sobre su interpretación en torno al alcance o tipos de alcance de la responsabilidad de los socios. A raíz de estas ambigüedades y tras años de negociación con agentes y representantes de trabajadores, fue aprobada la Ley 11/2019 de Cooperativas de Euskadi.

En ella, la solución al espinoso tema de la responsabilidad limitada o ilimitada de los socios, ha sido la de introducir la vía de realizar una ampliación de capital, amparándose en el carácter inversor que este mecanismo puede ofrecer a los socios. Parece que lo que se quiere conseguir por parte del legislador es la supervivencia de la sociedad cooperativa. Utiliza para ello el recurso de la ampliación de capital que goza, en teoría, al menos, de una doble virtualidad: la de servir para revertir la mala situación económica de las sociedades, por un lado, y de mecanismo inversor, por otro, lo que permite no minorar el patrimonio de los socios por la imputación de las pérdidas de la sociedad, aunque sea de una forma peculiar.

En conexión con lo anterior y con la responsabilidad de los socios cooperativistas, en lo que respecta a la baja del socio, el legislador vasco no ha tenido más remedio que aceptar la responsabilidad por los contratos contraídos durante su vinculación a la cooperativa, a fin de preservar la liquidez de la sociedad para hacer frente a las obligaciones devengadas. Se trata de una solución generalizada que, asimismo, busca aplicar un tratamiento igualitario para los socios que están en activo y los que se han dado de baja. 
Finalmente, cabe destacar que la fragmentación normativa en la materia constituye el reflejo de la diversidad de realidades existentes a nivel estatal. Ello conlleva, a su vez, la consiguiente diversidad en opiniones y criterios en la doctrina científica.

\section{Bibliografía}

ALFONSO SÁNCHEZ, R. 2009. "La legislación española sobre cooperativas y sociedades laborales: ¿una respuesta adecuada a las necesidades del sector?», CIRIEC-España. Revista jurídica de economía social y cooperativa, n. ${ }^{\circ} 20$, pp. $9-41$.

APARICIO, I.N. 2019. "Reflexiones sobre diversas cuestiones cooperativas (análisis principal bajo Ley Vasca)». Deusto Estudios Cooperativos, n. ${ }^{\circ} 13$, pp. 29-67.

BATALLER GRAU, J. (dir.), MARÍA VIDAL, S., MARÍN SANCHEZ M. ${ }^{a}$ del M., MATEOS RONCO, A., ELENA DIAZ, F. 1975-1976. «Ideas sobre una posible interpretación de las pérdidas del pasivo según la vigente ley»., Estudios cooperativos $n .^{\circ} 36-38$, pp. 190 y ss.

FAJARDO GARCÍA, G. 1997. La gestión de la cooperativa: responsabilidad de los socios, Tecnos, Madrid.

GAMINDE EGIA, EBA. 2018. "Régimen jurídico de la participación de los socios y socias en el capital de la cooperativa: tipos de aportación y derechos económicos». Boletín De La Asociación Internacional De Derecho Cooperativo, n. ${ }^{\circ} 53$ (diciembre), 207-24. https://doi.org/10.18543/baidc-532018pp207-224.

GONDRA ELGUEZABAL G. Y BILBAO ZORROZUA, A. 2019. "Alcance del régimen de responsabilidad de los socios en las cooperativas de viviendas en Euskadi», Revista Vasca de Economía Social, n. ${ }^{\circ} 16$, pp. 149-166, DOI: https://doi.org/10.1387/reves.21217.

GRIMALDOS GARCÍA, M.I. 2009. "El concurso de la cooperativa y su repercusión en el patrimonio personal de los socios», Revista de Derecho Concursal y Paraconcursal, n. ${ }^{\circ} 11$, pp. 323-343. https://www.mondragon.edu/documents/20182/625969/Aportacion+de+las+coop.+a+los+retos+tejido+pr oductivo+vasco+2018/ecd0df3c-72bc-4f4f-9f18-ce35d5821576,

MANRIQUE ROMERO, F. y RODRÍGUEZ POYO-GUERRERO, J.M. 1980. «La cOoperativa: garantías formales para su eficacia en el tráfico», Revista de Derecho Notarial, n. ${ }^{\circ}$ 109-110, pp. 29-155.

ORTEGA I. 2018. "Aportación de las Cooperativas al resto del tejido vasco». Universidad de Mondragón, consultado el 03/07/2020.

OTXOA ERRARTE R. 2019. "A propósito del Laudo del Servicio Vasco de Arbitraje Cooperativo n. ${ }^{\circ}$ 7/2018, del 20 de julio de 2018. Doble contabilidad y asunción de pérdidas», Revista Vasca de Economía Social, 16, pp.169-185, DOI: https://doi.org/10.1387/reves.21220. 
PANIAGUA, M. 2005. "La determinación y la distribución de los resultados del ejercicio económico en la Sociedad Cooperativa: propuestas de armonización legislativa», Revista de Derecho de Sociedades, n. ${ }^{\circ} 24$, pp. 199-229.

PAZ CANALEJO, N. 1979. El nuevo derecho cooperativo español, Digesa, Madrid.

SACRISTAN BERGIA, F. 2020. "Sobre la limitación de la responsabilidad de los socios cooperativistas», Boletín de la Asociación Internacional de Derecho Cooperativo, n. ${ }^{\circ}$ 57, Bilbao, pp.225-250, DOI: https://doi.org/10.18543/ baidc-57-2020pp225-251

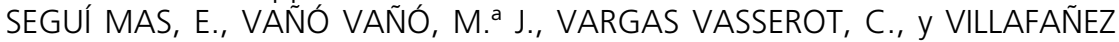
PEREZ, I. 2012. Pérdidas, disolución y concurso en sociedades cooperativas, Marcial Pons, Madrid.

SUSO VIDAL J.M. 2004. "La imputación de pérdidas al socio en la liquidación concursal cooperativa», Estudios sobre la ley Concursal. Libro homenaje a Manuel Olivencia, vol. 5, Marcial Pons, Madrid, pp. 4845-4876.

VARGAS VASSEROT, C. 2010. "El derecho de reembolso del socio en caso de baja y el concurso de las sociedades cooperativas», CIRIEC-España. Revista Jurídica de economía social y cooperativa, n. ${ }^{\circ} 21$, pp. 37-58.

VICENT CHULIÁ, F. 1994. Ley general de cooperativas, Tomo XX de los Comentario a al Código de comercio y Legislación mercantil Especial, vol. 3., Madrid.

VIGUERA REVUELTA, R. 2015. El Derecho de reembolso en las sociedades cooperativas, Tirant lo Blanch, Valencia.

VILLAFAÑEZ PEREZ, I. 2020. "El Régimen orgánico y económico de las cooperativas a la luz de la nueva Ley de cooperativas de Euskadi», Revista de derecho de sociedades, n. ${ }^{\circ}$ 60, Aranzadi. Edición en PDF. DOI: https://dialnet. unirioja.es/servlet/extart?codigo=7621638 - VILLAFAÑEZ PEREZ, I. 2014. Cooperativa y concurso. Estudio de las relaciones jurídicas con sus socios, Marcial Pons, Madrid.

VITERI ZUBIA, I. 2016. "La responsabilidad del socio cooperativista por las pérdidas sociales», CIRIEC-España. Revista Jurídica de economía social y cooperativa, n. ${ }^{\circ} 28$, pp. 209-246.

\section{Legislación}

Ley 4/1993, de 24 de junio, de Cooperativas de Euskadi (BOPV núm. 135, de 19 de julio de 1993) (BOE núm. 35, de 10 de febrero de 2012).

Ley 4/1999, de 30 de marzo, de cooperativas de la Comunidad de Madrid (BOCM núm. 87, de 14 de abril de 1994) (BOE núm. 131, de 2 de junio de 1999).

Ley 27/1999 de 16 de julio, de Cooperativas (BOE núm. 170, de 17 de julio de 1999).

Ley 4/2002, de 11 de abril, de Cooperativas de la Comunidad de Castilla y León (BOCL núm. 79, de 26 de abril de 2002) (BOE núm. 116, de 15 de mayo de 2002). 
Ley 18/2002, de 5 de julio, de Cooperativas de Catalunya (DOGC núm. 3679, de 17 de Julio de 2002) (BOE núm. 179 de 27 de Julio de 2002).

DECRETO 58/2005, de 29 de marzo, por el que se aprueba el Reglamento de la Ley de Cooperativas de Euskadi (BOPV núm. 73, de 19 de abril de 2005).

Ley Foral 14/2006, de 11 de diciembre, de Cooperativas de Navarra (BON núm. 149, de 13 de diciembre de 2006).

Ley 14/2011 de, 23 de diciembre, de Sociedades Cooperativas Andaluzas (BOJA núm. 26, de 8 de febrero de 2012) (BOE núm. 17, de 20 de enero de 2012).

Decreto Legislativo 2/2015, de 15 de mayo, del Consell por el que se aprueba el texto refundido de la Ley de Cooperativas de la Comunitat Valenciana (DOCV núm. 7529, de 20 de mayo de 2015).

Ley $11 / 2019$ de, 20 de diciembre, de Cooperativas de Euskadi (BOPV núm. 247, de 30 de diciembre de 2019) (BOE núm. 14, de 16 de enero de 2020). 


\section{Derechos de autor}

El Boletín de la Asociación Internacional de Derecho Cooperativo es una revista de acceso abierto lo que significa que es de libre acceso en su integridad inmediatamente después de la publicación de cada número. Se permite su lectura, la búsqueda, descarga, distribución y reutilización legal en cualquier tipo de soporte sólo para fines no comerciales y según lo previsto por la ley; sin la previa autorización de la Editorial (Universidad de Deusto) o el autor, siempre que la obra original sea debidamente citada (número, año, páginas y DOI si procede) y cualquier cambio en el original esté claramente indicado.

\section{Copyright}

The International Association of Cooperative Law Journal is an Open Access journal which means that it is free for full and immediate access, reading, search, download, distribution, and lawful reuse in any medium only for non-commercial purposes, without prior permission from the Publisher or the author; provided the original work is properly cited and any changes to the original are clearly indicated. 